\title{
Exploring mentorship programs and components in nursing academia: A qualitative study
}

\author{
Lorelli Nowell *, Deborah E. White, Karen Benzies, Patricia Rosenau \\ University of Calgary, Calgary, Alberta, Canada
}

Received: February 25, 2017

Accepted: March 27, 2017

Online Published: April 6, 2017

DOI: $10.5430 /$ jnep.v7n9p42

URL: https://doi.org/10.5430/jnep.v7n9p42

\begin{abstract}
Objective: Nursing education institutions globally have issued calls for mentorship to address the nursing faculty shortage; however, little is known about the current state of mentorship for faculty members in Canadian schools of nursing. The purpose of this study is to describe the current state of mentorship in Canadian schools of nursing and explore definitions and goals of mentorship programs, mentorship models and components, and mentorship evaluation.

Methods: A qualitative descriptive study was conducted. Within the Canadian Association of Schools of Nursing there are 81 English-speaking schools of nursing and 2,284 permanent faculty members spread over four regions. Participants were recruited from the 81 schools of nursing through the CASN newsletter list serve and publically accessible email addresses. Inclusion was limited to English speaking faculty. Purposive sampling aimed to capture variation across rank and tenure, school, size and areas within Canada. Semi-structured interviews were utilized to explore the participant's $(n=48)$ perspectives and involvement with mentorship. Interviews were audio-recorded and transcribed verbatim. NVivo was used to code and analyze the data for significant statements and phrases, which were organized into themes and sub-themes.

Results: Mentorship remains largely informal in nursing academia without common definitions or goals. Current mentorship in nursing academia employed dyad, peer, group, constellation, and distance mentorship models. Common mentorship program components included guidelines, training, professional development workshops, purposeful linking of mentors and mentees, and mentorship coordinators. Evaluation of mentorship in nursing academia, where it exists, remains mostly descriptive, anecdotal, and lacks common evaluative metrics.

Conclusions: Our results confirm mentorship in Canadian schools of nursing remains largely informal. In developing mentorship programs, academic leaders need to consider the mentorship models and components to meet their specific needs. Further rigorous evaluation of mentorship programs and components is needed to identify if mentorship programs are achieving specified goals.
\end{abstract}

Key Words: Mentorship, Nurses, Nursing, Academia, Qualitative study, Higher education

\section{INTRODUCTION}

Mentorship is a vital aspect of training, sustaining, and maintaining the nursing faculty workforce. ${ }^{[1]}$ Nursing education programs across jurisdictions are challenged by the shortage of registered nursing faculty. ${ }^{[2]}$ According to the World Health Organization ${ }^{[1]}$ the shortage of nurse faculty in the ma- jority of its member states is a key concern in the provision of human resources for healthcare. The Institute of Medicine of the National Academies ${ }^{[3]}$ argued that nurses have a responsibility to mentor those who come after them, and nursing organizations have a responsibility to provide mentoring and leadership guidance. From a global perspective, mentorship

*Correspondence: Lorelli Nowell; Email: lnowell@ucalgary.ca; Address: University of Calgary, 2500 University Drive NWCalgary, AB, T2N 1N4, Canada. 
in nursing academia provides structured guidance to new nursing faculty and may prevent the premature departure of those with potential to become future nursing leaders. ${ }^{[4-9]}$ The next generation of nurses will depend on strategic, focused plans to increase the pool of qualified nursing faculty.

Several studies have identified the need for mentoring programs in nursing academia. ${ }^{[6-8]}$ A recent systematic review, conducted by Wyte-Lake, $\operatorname{Tran}^{[9]}$ recommended the implementation of a mentorship program for new nursing faculty to provide guidance to those entering into academia. Despite the call for mentorship, research on mentorship in nursing academia is a relatively recent development.

The evidence base for mentorship has evolved in the business, medicine, and education literature. Systematic reviews on mentorship in corporate settings have reported increased job satisfaction, and perceived increases in career advancements opportunities for those that received mentor ship compared to those who did not. ${ }^{[10]}$ A systematic review of mentorship in academic medicine reported that mentorship has a significant influence on personal development, career guidance, career choice, and research productivity, recruitment, and retention. ${ }^{[11]}$ In a recent systematic review, mentorship had positive effects on behavioral, attitudinal, relational, motivational, and career outcomes for nurses working in academic settings. ${ }^{[12]}$ While the nursing literature contains numerous references to the importance of mentoring, mentorship in nursing academia is not an established standard practice.

The scarcity of information on mentorship is regrettable because this evidence is needed for nursing schools to implement mentorship programs. The lack of mentorship research and evaluative data leaves policy makers with limited guidance regarding which alternatives to consider when designing mentorship strategies. Significant resources are required to fund innovations, therefore, understanding the benefits and shortcomings of various strategies may ensure that scarce resources are devoted to the most efficient and effective strategies. Given the potential importance of mentoring in nursing academia, more research is needed to understand how mentorship is defined and described, what mentorship includes, and how mentorship is evaluated.

The overarching aim of this study was to identify the current state of mentorship in Canadian schools of nursing; and the research questions were the following:

(1) What are the goals of mentorship programs?

(2) How is mentorship defined?

(3) What mentorship models are utilized and how are they described?

(4) What are the components of current mentorship pro- grams and how are they described?

(5) How are current mentorship programs being evaluated?

\section{Methods}

\subsection{Design}

A qualitative descriptive design was used to gain a comprehensive understanding of mentorship. The research is presented according to the Consolidated Criteria for Reporting Qualitative Research (COREQ). ${ }^{[13]}$

\subsection{Sample and recruitment}

Participants were recruited from 81 English speaking schools of nursing in Canada. Based on results from a previously conducted survey about mentorship in nursing academia, of the 203 participants who agreed to be interviewed, 48 were purposively sampled to capture participants across rank and tenure including professoriate and instructors, $\mathrm{PhD}$ and masters prepared faculty, and those who focus on graduate and undergraduate education. Variation in school sizes, areas within Canada, and those with and without mentorship programs were sought. Permission to conduct this research was granted through the local University Health Research Ethics Board (REB15-0194). Local site arrangements were made to meet research governance requirements at individual schools of nursing.

\subsection{Data collection}

A semi-structured interview guide (see Table 1) was developed based on results from the previously conducted survey. The guide consisted of open-ended questions designed to explore both participant's perspectives and involvement with mentorship. Individual telephone and face-to face interviews were approximately 30-45 minutes in length. All interviews were conducted by LN and digitally-recorded and transcribed verbatim. Field notes were kept to capture researcher insights about mentorship throughout the interview process. Documents describing the structure, purpose, and progress of mentorship programs were obtained electronically from participants who were involved in formalized mentorship programs. Data collection continued until all provinces were adequately represented and data saturation was reached. Data were collected from January 2016-March 2016.

\subsection{Data analysis}

Thematic analysis methods were used to identify, organize, describe, and report themes found within our data set. Thematic analysis provides a rich and detailed, yet complex account of data through examining the perspectives of different research participants, highlighting similarities and differences, as well as generating unanticipated insights. ${ }^{[14]}$ The 
process of data collection and analysis occurred iteratively throughout the research process. Transcripts, documents, and researcher notes were assigned unique identifiers and imported into NVivo (version 10) to support the organization and coding of the data. A six step thematic analysis, as outlined by Braun and Clarke, ${ }^{[14]}$ guided an iterative and reflective process involving a constant moving back and forward between each of the phases. ${ }^{[14]}$

\subsection{Rigour}

Several techniques were used to maximize the trustworthiness of our study findings. Maximum variation sampling was used to gain the perspectives of the widest sample of participants and to ensure the variations across the provinces were adequately addressed. Data collection triangulation and prolonged engagement with the data were used to increase the probability of credible findings being produced. ${ }^{[15]}$ To achieve dependability we ensured our research process was logical, traceable, and clearly documented by creating an audit trail. ${ }^{[16,17]}$ All records of raw data, field notes, transcripts, and a reflexive journal to were kept to help systemize, relate, and cross reference data, as well as ease the reporting of the research process. ${ }^{[18]}$ A codebook was developed to facilitate coding and to maintain a research audit trail. The researchers (LN, DW, KB, PR) met frequently to establish authenticity and trustworthiness of the research, and to insure interpretations were clear to the readers and true to the data.

Table 1. Semi-structured interview questions
Semi-structured interview questions
- What are your current beliefs about mentorship?
- What is your experience with mentorship at your school of nursing?
- What barriers have you encountered with mentorship? How have you overcome these barriers?
- What has facilitated mentorship? How have you leveraged these facilitators?
- How is mentorship currently being evaluated?
- How do you think mentorship programs might be better developed, implemented, and evaluated?
- $\quad$ Are there any questions that you thought I might ask that I didn’t?

\section{RESULTS}

\subsection{Participant characteristics}

In total, 48 participants participated in semi-structured interviews. See Table 2 for characteristics of participants.

\subsection{Current state of mentorship}

Mentorship in nursing academia is largely informal: "there's no formal ... structure or process that's worked through" (P22). This is "different than when the school, as an organization, says we're going to have a mentorship program" (P20). Concerns were raised regarding the informal nature of mentorship describing current mentorship as " $a$ little bit a hit and miss" (P3), "haphazard" (P29) and, "flying by the seat of your pants” (P25). Informal mentorship may be more common than formal mentoring "because a lot of times there's not enough funding or dollars to be able to support a formal structure of mentoring" (P4).

\subsection{Mentorship goals}

The goals of mentorship programs were identified within the mentorship documents obtained from participants. Common mentorship goals were "to establish and maintain a dynamic environment of shared expertise within the culture of nursing faculty" (Document 2), "to facilitate scholarly and academic growth among new/early career faculty members" (Document 6), "to foster professional development" (Document 7), and to "promote communication and increase knowledge" (Document 8).

The goals of nursing faculty seeking mentorship were different depending on their position and years of experience. Inexperienced nursing faculty "really need and deserve the support of a good mentorship program to help them make that transition into a very different type of nursing practice" (P15). Nursing instructors generally sought mentorship "around teaching practice ... around what it means to be an academic" (P38). In comparison, associate nursing professors generally pursued mentorship to accelerate their research "in terms of research grant writing, review of grants and also, dissemination ... engaging the university community and others outside of the university community" (P16).

\subsection{Mentorship definitions}

Definitions of mentorship were also found within the mentorship documents. Some definitions were very broad, defining mentorship as "A relationship where an individual takes a special interest in helping another person develop into a successful professional" (Document 6), while others provided 
more depth:

Mentorship means an above average, developmental, caring, sharing, and mutually rewarding relationship where one person invests his or her time, know-how, and effort in enhancing another's growth in insight, perspective, wisdom as well as knowledge and skill ... to prepare that person for greater productivity, understanding, or achievement in the future (Document 2).

Someone who is there to help, support and guide another into a place of greater learning and usefulness... and that of a working relationship which extends mutual trust and respect. The mentorship process assists both the mentor and mentee in professional development as both grow from, and through, the experience (Document 7).

\subsection{Mentorship models}

A number of mentorship models were identified by the participants including dyad, peer, group, constellation, and distance mentorship models. These are described in further details below.

\subsubsection{Dyad mentorship model}

The traditional dyad model of mentorship, where mentees are paired with more experienced mentors, was the most frequently mentioned mentoring model. The following quote demonstrates how this model is commonly implemented:

New faculty are always paired with a more senior member and that is their mentor. . for a minimum of a year... they meet regularly throughout the term to- - that's their first go-to person for questions, for issues, for advice (P12).

Often this type of mentorship was informal and described as "hooking someone up informally when they're hired with someone who has been there a fulltime faculty" (P39). Following the initial mentor/mentee matching, there was little or no guidance on how to develop the relationship: "I match up each brand new teacher with a mentor in their level... then those two set up a mentorship partnership and I leave it up to them how they want to do that" (P1). Although many mentees were encouraged to develop mentoring relationship with the people they taught with, they were also encouraged to "keep an eye out for other people who you believe... you want to learn from" (P34). Only one participant spoke about support offered to the mentorship dyads: "we met with the dyad a couple of times in the course of the first year, just to make sure things were going well and to give them support as a dyad" (P17).

Table 2. Participant characteristics

\begin{tabular}{|c|c|c|}
\hline \multirow[t]{2}{*}{ Characteristic } & \multicolumn{2}{|c|}{$\mathbf{N}=\mathbf{4 8}$} \\
\hline & $\mathbf{n}$ & $\%$ \\
\hline \multicolumn{3}{|l|}{ CASN region } \\
\hline WNRCASN & 29 & 60 \\
\hline COUPN & 12 & 25 \\
\hline QRCASN & 1 & 2 \\
\hline ARCASN & 6 & 13 \\
\hline \multicolumn{3}{|l|}{ Number of faculty per school } \\
\hline Less than 50 & 24 & 50 \\
\hline More than 50 & 19 & 40 \\
\hline I don’t know & 5 & 10 \\
\hline \multicolumn{3}{|l|}{ Nursing programs offered } \\
\hline Bachelor’s degree only & 26 & 54 \\
\hline Graduate degrees in nursing & 22 & 46 \\
\hline \multicolumn{3}{|l|}{ Academic Rank } \\
\hline Instructor Rank & 16 & 33 \\
\hline Assistant Professor & 11 & 23 \\
\hline Associate Professor & 10 & 21 \\
\hline Professor & 5 & 10 \\
\hline Leadership & 6 & 13 \\
\hline \multicolumn{3}{|l|}{ Highest level of education } \\
\hline Bachelor’s degree & 2 & 4 \\
\hline Master’s degree & 22 & 46 \\
\hline $\mathrm{PhD}$ & 24 & 50 \\
\hline \multicolumn{3}{|l|}{ Years of experience } \\
\hline Less than a year & 3 & 6 \\
\hline $1-4$ years & 16 & 33 \\
\hline 5-9 years & 10 & 21 \\
\hline 10-14 years & 9 & 19 \\
\hline 15-19 years & 2 & 4 \\
\hline More than 20 years & 8 & 16 \\
\hline
\end{tabular}

Dyads were often created based on teaching assignments where "new faculty will be paired up in terms of co-teaching a course so ... that person isn't all alone within that course" (P21). The goals of dyad mentorship appeared to be more of an orientation to the role and faculty processes for teaching and or research. Some of the goals of the dyads were broad including to "teach some of the everyday practical things" (P6) or to "help them with learning the ropes in relation to teaching and possibly in relationship to supervising graduate students" (P10). Some offered more concrete support where "the new faculty member can invite the mentor to ...come to my class to observe and participate and give me feedback" (P48). One mentorship program outlined some potential goals of the dyad model of mentorship suggesting that "mentors can assist mentees in: oral presentations, writ- 
ing of manuscripts, development of grant applications, and "like-minded individuals who want to be mentored" (P4) or securing grants, gaining insight into the 'ins and outs' of creating an academic career as a scholar" (Document 6).

\subsubsection{Peer mentorship model}

Peer mentoring models consisted of two or more faculty members, similar in experience or rank, interacting as equal partners and mentors to achieve mutually determined goals. Newer faculty members who were involved in peer mentorship described how "newer individuals kind of joined together to mentor themselves" (P36). Some peer mentorship programs were more extensive bringing "new faculty together from across the different schools" (P25). For more seasoned faculty, the goals of peer mentorship included creating a "support system for our writing" (P26) or as demonstrated in the following quote, bringing together faculty with similar roles:

We have this adventure in graduate studies and everybody who supervises students comes together and we learn from one another about how to write reference letters and what a good reference letter looks like. How do we position students good for scholarships? How are we hiring them within our program of research or what experience are we giving them? What professional development opportunities are there for ourselves and each other...It gives us an opportunity to sit with one another and have conversations we'd otherwise wouldn't have (P46).

\subsubsection{Group mentorship model}

The group mentoring model involves one or more mentor(s) supporting a group of mentees who hold themselves individually and collectively accountable to a common purpose of learning and development. The reasons for creating group mentorship were often due to the lack of mentors to form more traditional mentorship dyads: "as a survival thing... we kind of now are working together with a group... three or four that all got hired at the same time" (P8). This mentorship model was most common in smaller faculties with less than 50 members. Some group mentorship models had one faculty member responsible for the mentorship of all new faculty: "Her position is to mentor new faculty coming in... getting them familiar with not just our curriculum but teaching strategies and how to manage a classroom ... things that are very new to us as nurses coming into academia." (P43). In some of the group mentoring models, time was allotted for the mentor(s) to take on the mentorship role while in other group mentorship scenarios there was no formal structure, rather a motivated mentor who took an interest in the development of a group of mentees. Mentors sought out a group decision was made that "anybody new who comes really needs that support and we will help them. We'll all work together and we continue to all work together all the time" (P17). Participants described how mentees were pleasantly surprized with the support garnered through the group mentorship experiences: "I have never had this experience before where people give me so much of their time and information and resources" (P17). This type of group mentorship was often informal and self-managed "just something that I'm just doing informally ... I'm just going to do it on my own and people are quite happy to come as part of the team and we're just going to work together" (P4).

\subsubsection{Constellation mentorship model}

Constellation mentoring models are comprised of one mentee who has more than one mentor. Multiple mentors take active interest and action to advance the mentees career by assisting with both personal and professional development. These models were more common for professor ranked faculty who were focused on both the teaching and research components of their role. Participants spoke about having a number of mentoring relationships for different needs: "they were assigned sort of a research mentor and a teaching mentor" (P25), and "certainly within different processes there are mentors ... in the tenure and promotion process there was someone that was assigned to me... in the undergraduate program ... a mentor was associated with me." (P28). There was also a noted effort to have mentors who were at different points in their career: "there will be two faculty who will help this individual a faculty who is newer to our environment and a faculty who is more senior" (P45).

Others spoke about the various mentors they had had over their career trajectory. "I've had many mentors in my career and some have been academics and others haven't" (P6), and "there have been different people at different times who have provided mentorship to me" (P28). Others spoke about the constant and transient nature of some of their mentoring relationship "there's kind of that formal, constant relationship, but then there's also people that pop in and out and who are really great and you learn from for specific things" (P28). Overall, participants who had experience constellation mentorship spoke about the benefits of these relationships:

"I've had excellent mentors... people that worked here when I got here and were able to or wanted to take a role in helping me understand the role of a faculty member and also support me in starting my career and then maintaining my career right through" (P23). 


\subsubsection{Distance mentorship model}

Distance mentorship occurs when mentees seek out mentors from other disciplines or other schools to adequately meet their needs. They maintain communication via email, telephone, or online video conferencing to overcome the physical distance between them "we check-in every week... my mentee is not physically at the same campus as myself so it's like a virtual mentorship" (P6). Participants spoke of the 'infancy' of their program as a reason for exploring distance mentorship: "for our nursing program right now we're a relatively new program, so you would have to go outside your discipline" (P26). The creation of new positions within the faculty was another motivation for exploring distance mentorship "when I had a research chair and I asked for mentorship and that mentor was actually the Dean of Medicine and not nursing... it was an opportunity to speak with a senior academic" (P16). Other participants spoke of mentors who had been part of their career development from various institutions and maintained consistent contact: "the three [closest] mentors that I have are at a distance” (P46).

\subsection{Mentorship components}

A number of common mentorship program components were identified in the interviews and mentorship documents. These components included guidelines, training, professional development workshops, purposeful linking of mentors and mentees, and mentorship coordinators. These components are described in further detail below.

\subsubsection{Guidelines}

The purpose of mentorship guidelines was "to provide a framework for nursing educators to help support and facilitate a mentoring culture within the School" and to "help integrate foundational beliefs about mentoring from both nursing and educational contexts" (Document 2). Some mentorship manuals outlined the principles of mentorship and described various mentoring relationships such as peer mentoring and group mentoring. They also offered a "nuts and bolts section which briefly answers common questions asked by new faculty" (Document 2). Other guidelines included the "Background and purpose of the mentorship program.... definition of mentorship... role of the mentor. . program objectives... mentee responsibilities" (Document 7), "mentor objectives. . mentee objectives. . and initial meeting as well as second, third and fourth mentorship meeting guidelines" (Document 8). Some participants acknowledged that the mentorship manual was helpful while others acknowledged that mentorship guidelines were a work in progress: "So we'll be working with this faculty and see what's working and what isn't working, etc., as we develop guidelines for mentorship" (P45). For some mentorship proPublished by Sciedu Press grams without guidelines, the mentoring relationships failed to develop: "[W]hen I first started here I was told that I had a formal mentor. . I don't think I've ever seen her... I don't know that she was ever told that she was going to be my mentor" (P41), and "for at least a couple of the faculty it fell apart and never happened, so there was no follow-up or anything with that" (P7).

\subsubsection{Training}

Some mentorship programs offered mentorship training. The content of this training was different within each program but specific training for mentors included "Importance and characteristics of good mentoring relationships. . Review of Mentoring Contract... Code of mentorship-confidentiality... Setting expectations for feedback... Art of asking for and accepting feedback... Introduction to learning styles" (Document 7). Some training was offered in the form of mentorship manuals that included topics such as, "[t]he role and responsibilities of the mentorship team... preparing to be a mentor.. getting to know your mentee... staying connected with your mentee" (Document 2).

Mentorship training was often interwoven with orientation. One participant commented that she didn't think you could separate orientation and mentoring because "if you don't give that person an effective orientation the mentoring is a little wasted, because you don't have the relationship and you don't know what it is that you need to know from your mentor" (P15). In some programs mentorship matching was part of the orientation, while in other programs the orientation was used as a way to begin establishing potential mentoring relationships: "introducing them to people and getting them to understand who is around and who can help and what that help might look like... that's been very valuable” (P17).

\subsubsection{Professional development workshops}

Many participants indicated that professional development workshops were an important part of the mentorship they received. Some mentorship programs had "monthly professional development sessions at lunchtime” (P1), while others offered "ongoing orientation activities to all of the different aspects of the educator role throughout the term" (P12). Some of the workshops were "set up like a Master's or PhD class" where participants were presented with "a number of articles to read to kind of get you thinking about whatever it be, about students or an education and then we're going to come together and have a discussion about that" (P13). Many of these sessions were open to all faculty where "anybody can attend... so it truly is an open door.. whatever topic that you feel that you need at that time and you can attend" (P27). The workshop topics varied including "formal teaching sessions on evaluative process, giving feedback. . 
red flags...policy" often delivered at specific times to cover "key points when people will need it" (P12). Professional development workshops provided opportunities for faculty members to come together and learn from each other.

\subsubsection{Linking mentors and mentees}

Most often new faculty were assigned a mentor by the Dean or Chair based on teaching assignments, while some matches appeared more purposeful "following a needs assessment" (Document 5). Some participants acknowledged consideration was given to personality matching "trying to think are these people who will go and work well together" (P15), while others indicated "there's no necessary matching up between interests" (P47). A number of participants indicated that formalized matching did not work, perhaps because the relational aspect of the relationship was missing. "We have tried to do mentorship informally in the past and kind of assign people as mentors.... we had three people come on and we assigned it and by the end of the year they all ended up with different informal mentors, just because of who they connected with" (P43). The mentoring matches may succeed or fail based on "whether or not you get along with them, whether or not you're like-minded", or if “you're working with a mentor that believes in your approach and believes in your teaching philosophy" because "if you don't have that connection, then that can be really unhelpful” (P44).

In some of the mentorship programs, mentors and mentees were given the opportunity to choose their mentorship matches. Often the choice of mentors was gradual and reciprocal where mentees "select on their own somebody who they might feel more comfortable with in terms of asking questions or going to" or mentors selected mentees where "a potential mentor reaching out to somebody that looks as if they might benefit from mentoring" (P10). Informal mentoring relationships were often developed independently and described as those that "come about naturally" (P46) where "people are inclined to connect with those that are ... teaching in the same course or they're on the same unit or they're in the same hospitals" (P42). It was also often described as a mutual friendship "where you just get along with somebody and you become friends with them and then you seek their guidance" (P44). New faculty often described having "to make their own way" (P29) and "depending on who is available to you and what knowledge you have of those people that could serve as mentors it could take place" (P35) while others described a thoughtful and deliberate selection:

I purposely sought out someone-I asked my $\mathrm{PhD}$ supervisor about the person who I felt would be a good mentor for me and I sought out someone who had a lot of experience, who I knew to be kind ... knew was on the tenure and promotion committee, so who knew the things I needed to do if I wanted to get tenure. So that worked out really well for me... I think it was important for me to choose someone to be a formal mentor (P28).

Involvement in mentorship was most often voluntary where "we did have to say if we were interested in mentoring somebody" (P6) or there were "established faculty members [who] volunteer", (P12) or "sign up or agree to be your mentor" (P19). Although "it's encouraged that everyone be a part or take a part... it also isn't something that you have to do or be a part of" (P13). In one formalized mentorship program "All the mentors will have agreed to take on this role and were selected due to their commitment to the nursing program, knowledge of the curriculum; school of nursing and institutional policies and skill as educators" (Document 5).

Networking opportunities were described by a number of participants as a way to get to know one another with the potential to develop informal mentor/mentee relationships. "We have sort of speed dating sort of beginning thing when new faculty start... and people get to know each other" (P8). The goals of mentorship networking opportunities were to "try to find people that either they thought were going to be supportive, like-minded, to help them" (P20). One participant described how networking opportunities allowed her to make connections with "people who can make introductions and move things along quickly for me" and this helped her to grow her own network "there's been a few key people and I've met people through the people they've introduced me to, who have gone onto introduce, so it's kind of like snowball sampling, but in network building” (P41). Participants valued the networking opportunities:

One of the very best pieces of it was the links that people formed with other people who were doing the same job... they'd meet other new nurses, new nurse teachers and they'd form connections that lasted for quite a long time. So that again said to me this is an important thing; the human connection seemed to be the very best (P17).

\subsubsection{Mentorship coordinator}

Mentorship coordinators were a key component to mentorship programs initiated in schools of nursing without graduate degree programs. Some of these mentorship programs had an assigned mentor who mentored all new faculty: "her position is to mentor new faculty coming in and ...part 
of that position has hours allocated to orient new faculty" (P43). The role of the mentorship coordinator was to carry out "various roles that attend to the ongoing support and professional development needs of the BSN faculty" (Document 3). Mentorship coordinators seemed to have the bigger picture over the long term and helps to keep both mentee and mentor on track:

That fulltime position is a very, very busy position, where each term that person does a number of activities. She does faculty orientation throughout the term. She holds not only formal orientation at the beginning of term for new faculty, but she also connects with people in the clinical area, visits people in clinical and shadows them and helps them develop their practice in clinical and in classroom. She pairs them up with experienced faculty and supports those pairs throughout the term. She also runs ongoing orientation activities to all of the different aspects of the educator role throughout the term.... And she also follows up with all of those faculty throughout the term, helping them identify what they need to grow with and how they can access resources (P12).

Those participants who had a dedicated person for mentorship indicated that "having a dedicated person is essential" because "having somebody do this off the side of their desk does not work. We tried that. Having it as an add-on to people's responsibilities did not work" (P12). It was clear that participants believed "having a dedicated individual... is essential to having this kind of program work and be effective" (P12).

\subsection{Mentorship Evaluation}

A final research questions was to identify how current mentorship programs are being evaluated. Participants identified that mentorship evaluation was conducted on an informal basis "I wouldn't say that there's a formal evaluation" (P23), "it's more informal" (P43), or "the evaluation is just really off the cuff. Thanks a lot guys, you've really helped me out" (P17). Anecdotal evaluation suggested that mentorship was successful: "if you talk to new faculty members they almost always tell you that there's a culture of support, a culture of learning and that really helps them in that role" (P12) or "I do know when it works well, but it's really just from observational experience" (P5). A few participants indicated that some more formalized evaluation was occurring with regards to mentorship programs. One participant indicated that she had a "small, non-funded research project to look at the Published by Sciedu Press outcomes" and the findings were used to make changes "it was from that we decide to go to self-selection and things like that" (P20). Others indicated that a faculty member "sends out a questionnaire to everyone to evaluate how it's working, what can be improved, what's going on" (P12). It appeared that the evaluative feedback gathered indicated positive responses to the mentorship program: "it's generally pretty good". Open ended mentorship evaluation questions located in mentorship documents included "Aspects of the faculty support \& mentorship program I found most helpful were:", and "Aspects of the faculty support \& mentorship program I found least helpful were:" and "How can the faculty support and mentorship program support me" (Document 1). None of the interview participants were able to share any mentorship evaluation data to be included in this study.

\section{Discussion}

The purpose of this study was to identify the current state of mentorship in Canadian schools of nursing. The goals of mentorship programs were identified and mentorship definitions were highlighted. A number of mentorship models and mentorship program components emerged from our data.

\subsection{Current state of mentorship}

Mentorship in nursing academia remains largely informal. Similarly in other disciplines, fewer than $20 \%$ of faculty members were found to have formal mentorship. ${ }^{[11]} \mathrm{Al}-$ though nursing education institutions globally have issued calls for mentorship ${ }^{[4]}$ our findings suggest mentorship is not yet common practice. We recommend more deliberate use of mentorship to meet the behavioral, career, attitudinal, relational, and motivational needs of nursing faculty members.

\subsection{Mentorship goals}

The goals for mentorship programs identified in this study were most commonly related to fostering the developing new faculty and socializing them into the role of educator. Other goals included the development of teaching scholarship and increasing research output and development. Individual goals for mentorship were different depending on rank and years of experience. There is an absence of literature recognizing and differentiating the goals of mid-career and late career faculty with those of new nursing faculty which highlights an important area for future mentorship research. Similar to other authors ${ }^{[19]}$ we recommend that before implementing mentorship programs, clear and transparent expectations for what the mentoring programs aims to achieve are shared broadly with all faculty members. 


\subsection{Mentorship definitions}

Confusion exists regarding the nature, definitions, and role of mentorship within nursing academia. This confusion is not specific to nursing but is reflected throughout much of the literature. ${ }^{[20]}$ The term 'mentoring' is often used interchangeably with the terms managing, counseling, coaching, training, advising, teaching, buddying, role modeling, and supervising. ${ }^{[10]}$ The image and activities of mentoring become cloudy and unclear when mentoring is mixed with these other terms. Differentiating mentoring from other commonly used connotations is helpful in clarifying the concept and understanding that mentoring may encompasses elements of all of these activities. In order to account for the benefits of mentorship we recommend a clear definition and common understanding of mentorship be developed (through a consensus conference or concept analysis) and utilized within nursing and other disciplines.

\subsection{Mentorship models}

Numerous mentorship models are being utilized in academic nursing. Although the traditional dyad model of mentorship, where mentees are paired with more experienced mentors, was the most frequently mentioned model, a lack of potential mentors may make this model more challenging to operationalize. Group mentorship may be a more viable mentorship model in light of the nursing faculty shortage. ${ }^{[2,3,21]}$ Within our study findings, group mentoring was found to optimize the limited number of mentor resources by providing a supportive group network for a diverse group of new faculty members. Others have found the group mentorship model to help in reducing the costs associated with recruiting and training clinical faculty, maximizing resources, and benefiting more mentees than would be possible with the traditional dyad model. ${ }^{[22-25]}$

The findings from this study, and the nursing literature, indicate that peer mentorship may be a useable model for mentees who are in a similar career trajectory and are looking for a safe environment to express apprehensions. ${ }^{[26,27]}$ Constellation mentoring models were also identified in our study and within the literature. Hadidi, Lindquist ${ }^{[28]}$ discussed how constellation mentoring allows mentees to experience mentors with different styles of mentoring and leadership. Conn ${ }^{[29]}$ identified that mentees with both local and national mentors provided the mentee with greater opportunities to expand their networks. Distance mentoring models were also identified in our study and others have suggested this model could be used to support faculty in under-resourced nursing programs, and could support mid-career nursing faculty who may benefit more from a mentoring relationship with a distance mentor than a local one. ${ }^{[30]}$
Although our study did not aim to explore the effectiveness of the different mentorship models, our findings suggest that these various models may be important as the majority of respondents reported a positive impact. We recommend further research be conducted on the strengths and limitations of the various mentorship models to provide decision makers with the information needed to most effectively design mentorship programs to meet their specific needs.

\subsection{Mentorship components}

The components of mentorship programs varied across schools of nursing. Some mentorship programs incorporated mentorship guidelines. Within the mentorship literature, mentorship guidelines were often found to be predetermined by those who developed mentorship programs. ${ }^{[22,24]}$ Other authors have recommended that mentorship participants be encouraged to work together to articulate the purpose of the mentorship relationship, roles of the participants, and set mentoring goals to bring direction and clarity to their mentoring responsibilities. ${ }^{[7,23,27,28,30-33]}$ We recommend that whether mentorship guidelines are predetermined or jointly developed, they be shared across the faculty to ensure a common understanding and expectations.

Some mentorship programs identified in this study included some form of mentorship training. Similar to our finding, other mentorship programs have included mentorship training and orientation as part of a larger orientation to the university and nursing faculty. ${ }^{[22,34]}$ Mentorship orientation and training has been recommended by others, ${ }^{[35,36]}$ but to the best of our knowledge, research has yet to examine the important content to include in mentorship orientation and training. We recommend further research to identify the most effective content and methods of mentorship training.

The thoughtful linking of mentors and mentees was another identified mentorship program component. In other studies, mentors and mentees were often paired based on educational background, similar professional experiences, teaching assignments, ${ }^{[32,34,37]}$ professional interests and mentee career goals $^{[28]}$ or based on their requests. ${ }^{[29,32,38-41]}$ Although it is clear that appropriate fit between mentors and mentees is an important aspect for creating a successful mentoring relationship, there has been no consensus in the nursing literature on how and why mentors and mentees should be matched. Others who have explored mentorship matching across disciplines have found that matching based on deep-level similarity (attitudes, values, beliefs, personality), experiential similarity (academic, discipline, rank, location), and interaction frequency were found to be predictive of quality mentoring relationships, while matching based on demographics, skill and ability (experience, training, education), and whether 
the relationship is formal or informal, were not predictive of successful matching. ${ }^{[35,42,43]}$ Relationship quality may have significant effects on mentorship outcomes so we recommend thoughtful matching, networking opportunities, and including mentors and mentees in the matching process. Creating opportunities for mentors and mentee to interact such as in a 'speed dating' environment may allow mentors and mentees an opportunity to get to know one another before establishing mentoring relationships matches.

Prior to implementing mentorship we recommend identifying local mentoring champions who are familiar with the faculty to publicly advocate for mentorship and increase faculty engagement. Specific skills and knowledge are required to develop and implement mentorship resources; therefore, potential workforce changes would include the creation of a new position to oversee the mentorship program. Faculty members interested in mentorship should also be supported and trained to acquire the necessary skills to become effective mentors and/or mentees.

\subsection{Mentorship evaluation}

To date evaluation of mentorship in nursing academia, where it exists, remains mostly descriptive, anecdotal, and lacks common evaluative metrics. Similar to our findings, evaluation is a well-documented gap and weakness in the mentorship literature. We recommend more research be conducted because without rigorous evaluation of mentorship programs and components, it is challenging to draw conclusions regarding the achievement of specified goals. To measure the impact of mentorship, qualitative and quantitative data could be collected by means of questionnaires, interviews, review of CV's, and numbers of participants engaged in mentorship. Measurements of short term outcomes could include career satisfaction, productivity, recruitment, work-life balance, and organizational climate. Measurements of longer term outcomes could include promotion, retention, and organizational culture.

\subsection{Strengths and limitations}

This study is strengthened by the inclusion of participants from a diverse range of nursing schools and roles across Canada, however, was limited by including only Englishspeaking schools of nursing. The inclusion of a variety of schools allowed us to explore the complexity and variation of mentorship to achieve the fullest understanding of this concept, however, comparison with schools of nursing in other countries would strengthen the research. We were limited in our inquiry by the documents provided to us. It is possible that other mentorship documents exist that were not available for inclusion in our analysis.

\section{Conclusion}

Our study describes the current state of mentorship in Canadian schools of nursing. Mentorship is a multifaceted phenomenon that may play a pivotal role in training and maintaining the nursing faculty workforce. Clear and transparent mentorship definitions and expectations are needed across the country to help move the mentorship agenda forward. Our results may be used in conjunction with nursing faculty vision and goals to inform the development of mentorship models and strategies to fit specific faculty needs. In addition to identifying the current state of mentorship this study highlights the need for more rigorous evaluation using robust, multi-site research designs to enhance our understanding of mentorship in nursing academia. Future research might be aimed at understanding the effectiveness of mentoring models and specific program components in order that scarce resources are applied to the most effective mentorship strategies.

\section{Conflicts of InTEREST Disclosure}

The authors declare that there is no conflict of interest.

\section{REFERENCES}

[1] World Health Organization. Transforming and Scaling up Health Professional Education and Training: Policy Brief on Faculty Development. Geneva, Switzerland: World Health Organization. 2013.

[2] Benner P, Sutphen M, Leonard V, et al. Educating nurses: a call for radical transformation. San Francisco: Jossey-Bass; 2010.

[3] Institute of Medicine of the National Academies. The future of nursing: leading change, advancing health. United States of America: The National Academies Press; 2011.

[4] Mentoring of nurse faculty. National League for Nursing; 2006

[5] Dunham-Taylor J, Lynn CW, Moore P, et al. What Goes Around Comes Around: Improving Faculty Retention Through More Effec- tive Mentoring. Journal of Professional Nursing. 2008; 24(6): 337346. https://doi.org/10.1016/j . profnurs . 2007.10.013

[6] Huybrecht S, Loeckx W, Quaeyhaegens Y, et al. Mentoring in nursing education: perceived characteristics of mentors and the consequences of mentorship. Selected papers from the 3rd International Nurse Education Conference: Nursing education in a global community 11-14 April, 2010, Sydney, Australia. 2011; 31(3): 274-8. https://doi.org/10.1016/j.nedt.2010.10.022

[7] Nick JM, Delahoyde TM, Prato DD, et al. Best practices in academic mentoring: a model for excellence. Nursing Research \& Practice. 2012: 1-9. https://doi.org/10.1155/2012/937906

[8] Sawatzky JAV, Enns CL. A Mentoring Needs Assessment: Validating Mentorship in Nursing Education. Journal of Professional Nursing. 
2009; 25(3): 145-50. https://doi.org/10.1016/j.profnurs .2009 .01 .003

[9] Wyte-Lake T, Tran K, Bowman C, et al. A systematic review of strategies to address the clinical nursing faculty shortage. Journal of Nursing Education. 2013; 52(5): 245-52. https ://doi .org/10.3 928/01484834-20130213-02

[10] Underhill CM. The effectiveness of mentoring programs in corporate settings: a meta-analytical review of the literature. Journal of Vocational Behavior. 2006; 68(2): 292-307. https://doi.org/10.101 $6 / j \cdot j v b .2005 .05 .003$

[11] Sambunjak D, Straus S, Marušić A. Mentoring in academic medicine: a systematic review. JAMA. 2006; 296(9): 1103-15. https ://doi . org/10.1001/jama.296.9.1103

[12] Nowell L, Norris JM, Mrklas K, et al. Mixed methods systematic review exploring mentorship outcomes in nursing academia. Journal of Advanced Nursing. 2017; 73(3): 527-544. https://doi.org/ $10.1111 / \mathrm{jan} .13152$

[13] Tong A, Sainsbury P, Craig J. Consolidated criteria for reporting qualitative research (COREQ): a 32-item checklist for interviews and focus groups. International Journal for Quality in Health Care. 2007; 19(6): 349-57. https://doi.org/10.1093/intqhc/mzm042

[14] Braun V, Clarke V. Using thematic analysis in psychology. Qualitative Research in Psychology. 2006; 3(2): 77-101. https ://doi .or g/10.1191/1478088706qp063oa

[15] Lincoln Y, Guba EG. Naturalistic inquiry. Newbury Park, CA: Sage 1985.

[16] Tobin GA, Begley CM. Methodological rigour within a qualitative framework. Journal of Advanced Nursing. 2004; 48(4): 388-96. https://doi.org/10.1111/j.1365-2648.2004.03207.x

[17] Koch T. Establishing rigour in qualitative research: The decision trail. Journal of Advanced Nursing. 1994; 19(5): 976-86. https: //doi.org/10.1111/j.1365-2648.1994.tb01177.x

[18] Halpren ES. Auditing naturalistic inquiries: The development and application of a model. [(Unpublished doctoral dissertation)]. In press 1983.

[19] Straus S, Johnson MO, Marquez C, et al. Characteristics of successful and failed mentoring relationships: A qualitative study across two academic health centers. Academic Medicine. 2013; 88(1): 82-9. https://doi.org/10.1097/ACM.0b013e31827647a0

[20] Bray L, Nettleton P. Assessor or mentor? Role confusion in professional education. Nurse Education Today. 2007; 27(8): 848-55. https://doi.org/10.1016/j.nedt.2006.11.006

[21] World Health Organization. Working together for health: The world health report. Geneva, Switzerland: WHO press; 2006.

[22] Blauvelt MJ, Spath ML. Passing the torch: a faculty mentoring program at one school of nursing. Nursing Education Perspectives. 2008; 29(1): 29-33. PMid:18330419

[23] Reid TP, Hinderer KA, Jarosinski JM, et al. Expert clinician to clinical teacher: Developing a faculty academy and mentoring initiative. Nurse Education in Practice. 2013; 13(4): 288-93. http: //dx.doi.org/10.1016/j.nepr.2013.03.022

[24] Alteen AM, Didham P, Stratton C. Reflecting, refueling, and reframing: a 10-year retrospective model for faculty development and its implications for nursing scholarship. Journal of Continuing Education in Nursing. 2009; 40(6): 267-72. PMid:19639916 https://doi.org/10.3928/00220124-20090522-06

[25] Matthew-Maich N, Mines C, Brown B, et al. Evolving as nurse educators in problem-based learning through a community of faculty development. Journal of Professional Nursing. 2007; 23(2): 75-82. PMid:17383599 https ://doi.org/10.1016/j.profnurs . 200 6.07 .004
[26] Heinrich KT, Oberleitner MG. How a faculty group's peer mentoring of each other's scholarship can enhance retention and recruitment. Journal of Professional Nursing. 2012; 28(1): 5-12. https://doi.org/10.1016/j.profnurs. 2011.06.002

[27] Bryant AL, Aizer BA, Perez A, et al. Development and implementation of a peer mentoring program for early career gerontological faculty. Journal of Nursing Scholarship. 2015; 47(3): 258-66. PMid:25808927 https://doi.org/10.1111/jnu.12135

[28] Hadidi NN, Lindquist R, Buckwalter K. Lighting the fire with mentoring relationships. Nurse Educator. 2013; 38(4): 157-63. PMid:23778045 https://doi.org/10.1097/NNE.0b013e3182 $96 \mathrm{dccc}$

[29] Conn VS. Preparing academic nursing's future leaders: The Robert Wood Johnson Foundation's nurse Faculty Scholar Program. Western Journal of Nursing Research. 2013; 35(9): 1104-6.

[30] Lasater K, Young PK, Mitchell CG, et al. Connecting in distance mentoring: Communication practices that work. Nurse Education Today. 2014; 34(4): 501-6. https ://doi.org/10.1016/j.nedt .2013.07.009

[31] Byrne G, Topping A, Kendall S, et al. Developing a national mentorship scheme to enhance the contribution of clinical academics to health care. Nurse Researcher. 2014;22(2):23-8. PMid:25423938 https://doi.org/10.7748/nr.22.2.23.e1288

[32] Baker SL. Nurse educator orientation: professional development that promotes retention. Journal of Continuing Education in Nursing. 2010; 41(9): 413-7. PMid:20506931 https://doi.org/10.392 8/00220124-20100503-02

[33] Slimmer L. A teaching mentorship program to facilitate excellence in teaching and learning. Journal of Professional Nursing. 2012; 28(3): 182-5. https://doi.org/10.1016/j.profnurs. 2011. 11.006

[34] Suplee PD, Gardner M. Fostering a Smooth Transition to the Faculty Role. Journal of Continuing Education in Nursing. 2009; 40(11): 514-20. PMid:19904865 https: //doi .org/10.3928/00220124 -20091023-09

[35] Allen TD, Eby LT, Lentz E. Mentorship Behaviors and Mentorship Quality Associated With Formal Mentoring Programs: Closing the Gap Between Research and Practice. Journal of Applied Psychology. 2006; 91(3): 567-78. PMid:16737355 https://doi .org/10.103 7/0021-9010.91.3.567

[36] Kram KE. Mentoring at work: Developmental relationships in organizational life. Boston, MD: University Press of America; 1988.

[37] Brannagan KB, Oriol M. A model for orientation and mentoring of online adjunct faculty in nursing. Nursing Education Perspectives. 2014; 35(2): 128-30. PMid:24783731 https://doi.org/10.548 $0 / 1536-5026-35.2 .128$

[38] Wilson CB, Brannan J, White A. A mentor-protege program for new faculty, Part II: Stories of mentors. Journal of Nursing Education. 2010; 49(12): 665-71. PMid:20669870 https://doi .org/10.3 928/01484834-20100730-08

[39] White A, Brannan J, Wilson CB. A mentor-protege program for new faculty, part I: stories of proteges. Journal of Nursing Education. 2010; 49(11): 601-7. PMid:20672778 https ://doi .org/10.392 8/01484834-20100630-04

[40] Gilbert C, Womack B. Successful transition from expert nurse to novice educator? Expert educator: it's about you! Teaching \& Learning in Nursing. 2012; 7(3): 100-2. https://doi .org/10.1016/j . teln.2012.01.004

[41] Hickey KT, Hodges EA, Thomas TL, et al. Initial evaluation of the Robert Wood Johnson Foundation Nurse Faculty Scholars program. Nursing Outlook. 2014; 62(6): 394-401. PMid:25085329 https://doi.org/10.1016/j.outlook.2014.06.004 
[42] Eby LT, Allen TD, Evans SC, et al. Does mentoring matter? A multidisciplinary meta-analysis comparing mentored and non-mentored individuals. Journal of Vocational Behavior. 2008; 72(2): 254-67. https://doi.org/10.1016/j.jvb.2007.04.005
[43] Allen T, Eby L, Poteet M, et al. Career benefits associated with mentoring for protégés: A meta-analysis. Journal of Applied Psychology. 2004; 89(1): 127-36. https://doi.org/10.1037/0021-9010. 89.1 .127 